\title{
The clinical utility of tuberculin skin test and interferon- $\gamma$ release assay in the diagnosis of active tuberculosis among young adults: a prospective observational study
}

\author{
Ji Eun Lee ${ }^{1}$, Hee-Jin Kim² and Sei Won Lee ${ }^{1,3^{*}}$
}

\begin{abstract}
Background: The roles of the tuberculin skin test (TST) and QuantiFERON ${ }^{\circledR}$-TB Gold In-Tube assay (QFT-IT) in the diagnosis of active tuberculosis (TB) are not clear in young adults. We evaluated the diagnostic accuracy of the TST and QFT-IT in smear-negative TB among young adults with no underlying disease.

Methods: We prospectively enrolled 166 young participants 20-29 years of age with suspected active TB in a military hospital of South Korea. The TST and QFT-IT were performed for all participants.

Results: Of the 143 patients included in the analysis, active TB was diagnosed in 100 (69.9\%). There were 141 male patients, none of whom had immunosuppressive disease. The sensitivity, specificity, positive predictive value (PPV), and negative predictive value (NPV) of TST were 94\% (95\% Cl, 87-98\%), 88\% (95\% Cl, 74-96\%), 95\% (95\% Cl, 8898\%), and $86 \%(95 \% \mathrm{Cl}, 72-94 \%)$, respectively. The sensitivity, specificity, PPV, and NPV of the QFT-IT were 93\% (95\% Cl, 86-97\%), 95\% (95\% Cl, 81-99\%), 98\% (95\% Cl, 92-99\%), and 84\% (95\% Cl, 69-93\%), respectively. No significant differences were found between the TST and QFT-IT in any statistic.

Conclusions: Both the TST and QFT-IT showed high sensitivity and specificity in differentiating active TB from other diseases. The diagnostic accuracy of these two tests did not differ significantly when applied to this clinical population of young, immunocompetent adults in whom neonatal BCG vaccination was common, there was no history of previous TB and in whom suspicion of TB was high.
\end{abstract}

Trial registration: ClinicalTrials.gov: NCT00982969

\section{Background}

Tuberculosis (TB) is an important public health problem worldwide. In 2007, there were 9.27 million cases of TB, and 1.3 million deaths occurred among HIV-negative TB cases [1]. South Korea has an intermediate TB burden; the incidence of new cases is 90 per 100000 people per year despite an intensive effort for disease control [2]. A prompt and accurate diagnosis is critical for effective control and management of TB, but conventional diagnostic methods have their limitations. Completion of mycobacteria culture takes 3-8 weeks on solid

\footnotetext{
* Correspondence: seiwon@snubh.org

'Department of Internal Medicine, Armed Forces Capital Hospital,

Seongnam-si, Gyeonggi-do, Republic of Korea

Full list of author information is available at the end of the article
}

medium and 7-21 days in liquid medium [3,4]. The sensitivity of acid-fast bacilli (AFB) smears is low [3]. The polymerase chain reaction test is often used for rapid microbiological diagnosis of TB, but its sensitivity for smear-negative respiratory samples ranges from 48 to $53 \%[3,5,6]$.

The tuberculin skin test (TST) and whole-blood interferon- $\gamma$ release assay (IGRA) have been employed for diagnosing latent TB infection (LTBI), but they have also been investigated for their usefulness in the diagnosis of active TB. Although the IGRA is considered to be more useful than the TST in differentiating active TB [7-9], it has not been shown to be adequate for use as a rule-out test for active TB, with a pooled sensitivity and specificity of $80 \%$ [10]. However, in some populations, a higher sensitivity
Ciomed Central

() 2011 Lee et al; licensee BioMed Central Ltd. This is an Open Access article distributed under the terms of the Creative Commons Attribution License (http://creativecommons.org/licenses/by/2.0), which permits unrestricted use, distribution, and reproduction in any medium, provided the original work is properly cited. 
and specificity of more than $90 \%$ were reported $[11,12]$, which suggests that the IGRA may be utilized in selected populations. The TST has low specificity in Bacille Calmette-Guérin (BCG)-vaccinated populations [13,14] and several disadvantages compared with IGRA, but it is inexpensive and simple, facilitating its use in the community and in resource-limited settings [15].

Young adults have some distinctive characteristics. They are immunologically active and have a shorter duration of unknown TB exposure than do elderly people. Furthermore, nontuberculous mycobacteria (NTM) sensitization is not prevalent in this group, and more than 10 years have passed since their BCG vaccination at birth. The clinical utility of the TST and IGRA may differ by age, and the rates of positive TST results were found to be significantly higher in younger than in elderly patients ( $70 \%$ vs. $27 \%$, respectively) [8]. We evaluated the diagnostic accuracy of the TST and IGRA in the diagnosis of smear-negative TB in young and immunocompetent adults in the Korean military, where the IGRA is not usually available.

\section{Methods}

\section{Participants and data collection}

We prospectively enrolled all individuals 20 to 29 years old who were highly suspect for $\mathrm{TB}$ at the Armed Forces Capital Hospital, a central military referral hospital in Korea, between May 2008 and September 2009. Subjects who had a previous history of TB or who had taken anti-TB medication for more than 1 month before the visit were excluded. After giving informed consent, each participant was asked to complete a questionnaire about his or her demographics, previous history of TB, smoking status, and other factors. In addition, the TST and QuantiFERON ${ }^{\circledR}$-TB Gold In-tube assay (QFT-IT; Celletis Ltd., Victoria, Australia) were performed on all participants. This study was reviewed and approved by the Institutional Review Board of the Armed Forces Medical Command.

\section{Tuberculin skin test}

The TST was performed after blood sampling for QFTIT by trained personnel following standard procedures. For this test, $0.1 \mathrm{~mL}(2 \mathrm{TU})$ purified protein derivate (RT23; Statens Serum Institute, Copenhagen, Denmark) was injected intradermally into the inner side of the left forearm by three experienced nurses. Transverse induration at the TST site was measured in mm after 48-72 $\mathrm{h}$ by an experienced physician (Dr. S. W. Lee). We defined a positive test as an induration of $\geq 10 \mathrm{~mm}$ [16].

\section{Interferon-gamma release assay}

QFT-IT, a type of IGRA, was performed according to the manufacturer's instructions. Blood samples were collected in three special tubes: one coated with the Mycobacterium tuberculosis (MTB)-specific peptides ESAT-6, CFP-10, and TB 7.7 (Rv2654, only peptide 4); one with mitogen as a positive control; and one without antigen as a negative control. Within $8 \mathrm{~h}$ of blood sampling, tubes were incubated for $24 \mathrm{~h}$ at $37^{\circ} \mathrm{C}$, followed by centrifugation and cold storage until testing, as specified by the manufacturer. The concentration of IFN- $\gamma$ in plasma was measured using a commercial QFT-IT ELISA. The test result was determined as negative, intermediate, or positive (cutoff at $0.35 \mathrm{IU} / \mathrm{mL}$ and $\geq 25 \%$ of the nil control) by the manufacturer's software. The doctors in charge were blinded to the QFT-IT result prior to diagnosis.

\section{Definitions and diagnoses}

Final diagnoses were made on the basis of all clinical, radiologic, microbiologic, and pathologic information.

Active TB cases were defined as follows:

\section{Active pulmonary $T B$}

Active pulmonary TB was defined if: (i) MTB was cultured from sputum, bronchial specimens or (ii) patient data met the definition of a clinical case of $\mathrm{TB}$, according to the WHO [17]. For clinical cases of TB, radiographic lesions compatible with active TB upon HRCT were mandatory. Active pulmonary TB was defined as the presence of cavities, branching linear opacity, or multiple non-calcified nodules upon HRCT. However, lesions that appeared mainly as calcified nodules or fibrotic bands were excluded from the diagnosis of active TB [17-19]. In participants with lesions that suggested active TB, but who did not have positive acid-fast smears or culture of M. tuberculosis, broad-spectrum antibiotics (combination of a third-generation cephalosporin and a macrolide) were prescribed for 1 week. If the lesions on chest X-ray (CXR) or HRCT showed definite improvement, a diagnosis of active TB was excluded.

\section{Pleural TB}

Pleural TB was diagnosed if: (i) M. tuberculosis was detected in the culture of pleural fluid or tissue, or (ii) exudative pleural effusion showed lymphocyte predominance, negative cytology, low carcinoembryonic antigen $(<5 \mathrm{ng} / \mathrm{ml})$ and high adenosine deaminase ( $\geq 50 \mathrm{IU} / \mathrm{l})$.

\section{Lymph node $T B$}

Lymph node TB was diagnosed if one of the following criteria: (i) detection of M. tuberculosis in a culture or of lymph node tissue, (ii) pathological changes consistent with TB or, (iii) positive real-time polymerase chain reaction for M. tuberculosis in the tissue of lymph nodes confirmed by commercialized kit $\left(\mathrm{COBAS}^{\circledR}\right.$ TaqMan $^{\circledR}$ MTB test, Roche, West Sussex, UK) and a distinct clinical response to a anti-TB medication.

The diagnosis of other types of extrapulmonary TB was made prospectively on the basis of clinical manifestation consistent with TB and cultures of M. tuberculosis. 
Cases were defined as non-TB only when another definite diagnosis had been made.

\section{Pneumonia}

Pneumonia was defined as a new pulmonary infiltrate associated with at least one of the following factors: a new or increased cough, abnormal temperature $\left(<35.8^{\circ} \mathrm{C}\right.$ or $>37.8^{\circ} \mathrm{C}$ ), or an abnormal leukocyte count (leukocytosis, leukopenia, or the presence of immature neutrophils). We confirmed the resolution of the pulmonary infiltrate after administrating broad-spectrum antibiotics.

\section{Pulmonary paragonimiasis}

Pulmonary paragonimiasis was diagnosed by detection of parasite ova in sputum and/or stools. In egg-negative cases with peripheral eosinophilia and suspicious radiologic findings including patchy densities, cavities, pleural effusions, and ring shadows, elevated serum specific IgG antibody concentration for Paragonimus westermani helped to confirm the diagnosis.

\section{Empyema}

Empyema refers to a grossly purulent pleural effusion associated with pneumonia.

\section{Statistical methods}

Using active TB as the gold standard, we classified the results of TST and QFT-IT as true positive (TP), false negative (FN), false positive (FP), or true negative (TN). The sensitivity $(\mathrm{TP} /[\mathrm{TP}+\mathrm{FN}])$, specificity $(\mathrm{TN} /[\mathrm{TN}+$ $\mathrm{FP}])$, positive predictive value (PPV) (TP/[TP + FP]), negative predictive value (NPV) $(\mathrm{TN} /[\mathrm{TN}+\mathrm{FN}])$, positive likelihood ratio $(L R+)$ (sensitivity/[1 - specificity]), and negative likelihood ratio (LR-) ([1 - sensitivity]/specificity) were calculated for each diagnostic test. The area under the curve (AUC) of the receiver operating characteristic curve (ROC) was calculated to measure the overall accuracy of the test. Ninety-five percent confidence intervals (CIs) were estimated according to the binominal distribution. A $\chi^{2}$ test was used to compare the positive $p$-values, for which $<0.05$ was considered significant. Concordance between test results from the TST and QFT-IT was assessed using $\kappa$ coefficients [20]. Statistical analyses were performed using STATA 10.1 software (STATA Corp., College Station, TX, USA).

\section{Results}

\section{Baseline characteristics of the study populations}

A total of 166 patients were recruited, 23 of whom were excluded from the final analysis because their sputum smear results were positive. All patients were HIV negative, and no patient had risk factors for immunosuppression. A BCG scar was present in 102 patients (71.3\%). Active TB was diagnosed in 100 (69.9\%) patients. Forty-three patients (30.1\%) were classified as non-TB cases. Pneumonia was the most common diagnosis among non-TB cases. Compared to non-TB cases, TB cases had a significantly higher percentage of patients with sputum. Concerning the laboratory data, TB cases had a significantly lower peak body temperature and serum CRP concentration (Table 1).

Five patients were not able to expectorate sputum. One of the five patients had MTB isolated in his bronchial washing fluid. Three of the five presented with cervical lymphadenopathy (LAP); one was diagnosed with malignant lymphoma on pathologic exam, and the other two were diagnosed with reactive LAP because the enlarged lymph nodes became smaller with resolution of symptoms during follow-up. The last of the five patients was diagnosed with paragonimiasis; this patient had a peripheral eosinophilia, eosinophil-dominant pleural effusion, and elevated serum-specific IgG antibody concentration for $P$. westermani. MTB was not isolated in the AFB culture of his pleural fluid.

Table 1 Baseline characteristics of the study population

\begin{tabular}{|c|c|c|c|}
\hline Characteristics & $\begin{array}{c}\text { TB } \\
(n=100)\end{array}$ & $\begin{array}{l}\text { Non-TB } \\
(n=43)\end{array}$ & $P$ value \\
\hline Age, median(range), yrs & $22(20-30)$ & $21(20-26)$ & 0.02 \\
\hline Male Gender & 98(98) & $43(100)$ & 0.87 \\
\hline \multicolumn{4}{|l|}{ Smoking History } \\
\hline Non-smoker & $50(50.0)$ & $22(51.2)$ & 0.46 \\
\hline Ex-smoker & $3(3.0)$ & $4(9.3)$ & \\
\hline Current smoker & $47(47.0)$ & $17(39.5)$ & \\
\hline BCG scar present & $70(70.0)$ & $32(74.4)$ & 0.59 \\
\hline \multicolumn{4}{|l|}{ Sputum AFB smear } \\
\hline Negative & 99(99.0) & 39(90.7) & $<0.05$ \\
\hline Non-productive & $1(1.0)^{*}$ & $4(9.3)^{\dagger}$ & \\
\hline \multicolumn{4}{|l|}{ Symptom present } \\
\hline Cough & $52(52.0)$ & $29(67.4)$ & 0.09 \\
\hline Sputum & 39(39.0) & $28(65.1)$ & $<0.01$ \\
\hline Hemoptysis & 10(10.0) & $8(18.6)$ & 0.15 \\
\hline Peak $\mathrm{BT}\left({ }^{\circ} \mathrm{C}\right)$, mean $\pm \mathrm{SD}$ & $37.1 \pm 0.8$ & $37.6 \pm 1.1$ & 0.01 \\
\hline WBC $\left(\times 10^{3}\right.$ cells/uL $)$, mean $\pm S D$ & $6.89 \pm 1.85$ & $8.33 \pm 5.21$ & 0.09 \\
\hline $\mathrm{CRP}(\mathrm{mg} / \mathrm{dL})$, mean $\pm \mathrm{SD}$ & $2.02 \pm 3.32$ & $6.35 \pm 8.98$ & $<0.01$ \\
\hline \multicolumn{4}{|l|}{ Final Diagnosis } \\
\hline $\begin{array}{l}\text { Culture-positive } \\
\text { pulmonary TB }\end{array}$ & $41(41.0)$ & & \\
\hline Clinical pulmonary TB & $35(35.0)$ & & \\
\hline Extrapulmonary TB & $24(24.0)$ & & \\
\hline Pleural TB & 19(19.0) & & \\
\hline Lymph node TB & $2(2.0)$ & & \\
\hline Other site & $3(3.0)$ & & \\
\hline Pneumonia & & $30(69.8)$ & \\
\hline Paragonimiasis & & $3(7.0)$ & \\
\hline Empyema & & $2(4.7)$ & \\
\hline Other diagnoses & & 8(18.6) & \\
\hline
\end{tabular}

Data are no.(\%) of patients, unless otherwise indicated.

BCG, Bacille Calmette-Guerin; BT, body temperature; WBC, white blood cell; CRP, C-reactive protein; AFB, acid-fast bacilli; TB, tuberculosis.

* Mycobacterium tuberculosis was isolated on bronchial washing fluid.

${ }^{\dagger}$ Four subjects include two with reactive lymphadenopathy, one with malignant lymphoma and one with paragonimiasis. 


\section{Diagnostic accuracy of TST, and QFT-IT}

Of 142 patients with available TST results, the results were positive in 98 (69.0\%), 93 of whom were diagnosed with active TB; the results were negative in 44 (31.0\%) patients, six of whom was diagnosed with active TB. Of the 143 patients who underwent QFT-IT tests, five patients $(3.5 \%)$ had an indeterminate result. The results of QFT-IT were positive in 95 patients (66.4\%), 93 of whom were diagnosed with active $\mathrm{TB}$; the results were negative in 43 (30.1\%), seven of whom were diagnosed with active TB (Table 2).

The TST sensitivity for the diagnosis of active TB was $94 \%$ (95\% CI, 87-98\%), and the specificity was 88\% (95\% CI, 74-96\%). The QFT-IT sensitivity was 93\% (95\% CI, $86-97 \%$ ), and the specificity was 95\% (95\% CI, 81-99\%). None of the four statistics was significantly different between the TST and QFT-IT, revealing excellent agreement between the two assays $(\kappa=0.83$, with exclusion of five indeterminate results in QFT-IT, $P<0.001$, Table 3).

\section{Clinical findings of the participants with indeterminate QFT-IT results}

Five patients showed indeterminate QFT-IT results; all were non-TB cases. Four patients had bacterial pneumonia, and one patient had empyema. One patient showed severe lymphocytopenia (Patient 2), and three patients (Patients 1-3) showed low serum albumin concentrations (Table 4).

\section{Discussion}

Our study showed that both the TST and QFT-IT had high sensitivity and specificity in the diagnosis of active TB among young military personnel in South Korea. The specificity for both tests was higher than that previously reported in South Korea [7,21], and that of the TST (88\%) was slightly lower than that of the QFT-IT (95\%); however, the difference was not statistically significant $(p=0.53)$.

There are two possible explanations for the higher sensitivities and specificities compared with those in previous reports. First, false-positive TST reactions due to

Table 2 The results of TST and QFT-IT among active TB and non-TB disease

\begin{tabular}{|c|c|c|c|c|c|c|}
\hline & \multicolumn{2}{|c|}{ TST $\left(n=142^{*}\right)$} & \multirow[t]{2}{*}{ Total } & \multicolumn{2}{|c|}{ QFT-IT $\left(n=138^{\dagger}\right)$} & \multirow[t]{2}{*}{ Total } \\
\hline & positive & negative & & positive & negative & \\
\hline $\mathrm{TB}$ & 93 & 6 & 99 & 93 & 7 & 100 \\
\hline Non-TB & 5 & 38 & 43 & 2 & 36 & 38 \\
\hline Total & 98 & 44 & 142 & 95 & 43 & 138 \\
\hline
\end{tabular}

TB, tuberculosis; TST, tuberculin skin test; QFT-IT, QuantiFERON ${ }^{\circledR}$ TB Gold InTube assay.

*TST result was not available in one TB patient.

${ }^{+}$QFT-IT results were indeterminate in five non-TB patients.
Table 3 Diagnostic accuracy of TST and QFT-IT in the diagnosis of active TB

\begin{tabular}{lccc}
\hline & TST $(\mathbf{n}=\mathbf{1 4 2})$ & QFT-IT $(\mathbf{n}=\mathbf{1 3 8})$ & $\boldsymbol{P}$ value \\
\hline Sensitivity, \% (95\% Cl) & $94(87-98)$ & $93(86-97)$ & 0.79 \\
Specificity, \% (95\% Cl) & $88(74-96)$ & $95(81-99)$ & 0.53 \\
PPV, \% (95\% Cl) & $95(88-98)$ & $98(92-99)$ & 0.47 \\
NPV, \% (95\% Cl) & $86(72-94)$ & $84(69-93)$ & 0.73 \\
LR+ (95\% Cl) & $8.1(3.5-18.4)$ & $17.7(4.6-68.2)$ & \\
LR- (95\% Cl) & $0.07(0.03-0.15)$ & $0.07(0.04-0.15)$ & \\
AUC (95\% Cl) & $0.91(0.85-0.97)$ & $0.94(0.89-0.99)$ & \\
\hline
\end{tabular}

PPV, positive predictive value; NPV, negative predictive value, $\mathrm{LR}+$, positive likelihood ratio; LR-, negative likelihood ratio; AUC, area under curve; TST, tuberculin skin test; QFT-IT, QuantiFERON ${ }^{\circledR}$ TB Gold In-Tube assay

BCG vaccination in infancy become minimal in young adults. In a review of 24 published studies regarding the effect of BCG vaccination on TST, only $1 \%$ of subjects vaccinated as infants were TST-positive if tested $\geq 10$ years after BCG [15]. The prevalence of a positive TST has also been correlated with the number of BCG scars, a proxy for older age when last vaccinated [22,23]. BCG revaccination in individuals 12 to 13 years of age was discontinued in South Korea in 1997 based on a WHO recommendation [24]. Of the 143 patients enrolled in this study, only two patients had two BCG scars. Second, this study enrolled young and immune-competent adults. The median age of previous studies that reported lower specificities was 55 years [7]. The sensitivities of the IGRA are known to decrease significantly with older age [8], HIV infection [25], and chronic renal failure [26].

Previous studies in which the IGRA had a higher sensitivity than that of the TST [14,27] suggest that the IGRA may be more useful in the diagnostic exclusion of active TB. In a recent meta-analysis of IGRA for detecting active TB, the pooled sensitivity of the QFT-IT (81\%; 95\% CI, 78$83 \%$ ) among definitively confirmed TB cases was higher than that of the TST (70\%; 95\% CI, 67-72\%) [13]. However, few studies have compared the performances of the TST and IGRA in young adults. In a Japanese study on the clinical utility of the QFT-2G test for elderly patients with active TB, the rates of positive TST results were significantly higher in younger patients (27\% vs. $70 \%)$ [8]. We assumed that the sensitivity of the TST would be comparable to that of the QFT-IT in young, previously healthy adults, and the sensitivity of the TST (94\%) and QFT-IT (93\%) showed no statistically significant difference ( $p=$ 0.79 ) in this study. However, considering the difference in positive likelihood ratio between TST and QFT-IT(8.1 vs 17.7), TST is expected to be less useful than QFT-IT for ruling in active TB as the post-test probability falls below $50 \%$.

Indeterminate QFT-2G results were more common in patients receiving immunosuppressive therapy, especially those with lymphocytopenia [28]. One patient had 
Table 4 Clinical findings of the participants with indeterminate QFT-IT results

\begin{tabular}{|c|c|c|c|c|c|c|c|c|c|c|c|}
\hline $\begin{array}{l}\text { Patient } \\
\text { No. }\end{array}$ & QFT-IT result & Age & $\begin{array}{l}\text { BCG } \\
\text { scar }\end{array}$ & $\begin{array}{c}\text { WBC } \\
\text { (cells/uL) }\end{array}$ & $\begin{array}{l}\text { Lymphocyte count } \\
\text { (cells/uL) }\end{array}$ & $\begin{array}{c}\text { Serum total Protein } \\
(\mathrm{mg} / \mathrm{dL})\end{array}$ & $\begin{array}{l}\text { Serum albumin } \\
(\mathrm{mg} / \mathrm{dL})\end{array}$ & $\begin{array}{l}\text { TST } \\
(\mathrm{mm})\end{array}$ & $\begin{array}{l}\text { AFB Smear/Culture in sputum } \\
\text { examination }\end{array}$ & $\begin{array}{l}\text { Radiologic } \\
\text { finding }\end{array}$ & Diagnosis \\
\hline 1 & Indeterminate & 22 & Yes & 10,390 & 1,039 & 6.4 & 3.3 & 0 & $-/-$ & $\begin{array}{c}\text { Multifocal } \\
\text { consolidations }\end{array}$ & Pneumonia \\
\hline 2 & Indeterminate & 21 & Yes & 28,180 & 366 & 5.9 & 3.2 & 0 & $-/-$ & LLL consolidation & Pneumonia \\
\hline 3 & Indeterminate & 20 & Yes & 7,110 & 683 & 5.3 & 2.8 & 0 & $-/$ & $\begin{array}{c}\text { Multifocal } \\
\text { consolidations }\end{array}$ & Pneumonia \\
\hline 4 & Indeterminate & 23 & Yes & 10,620 & 1,296 & 7.6 & 4.2 & 0 & - & $\begin{array}{c}\text { RML, RLL } \\
\text { consolidations }\end{array}$ & Empyema \\
\hline 5 & Indeterminate & 20 & Yes & 9,460 & 1,296 & 8.1 & 4.2 & 0 & $-/-$ & RLL consolidation & Pneumonia \\
\hline
\end{tabular}

QFT-IT, QuantiFERON ${ }^{\circledR}$ TB Gold In-Tube assay; BCG, Bacille Calmette-Guerin; WBC, white blood cells; TST, tuberculin skin test; AFB, acid-fast bacilli; RML, right middle lobe; LUL, left upper lobe; LLL, left lower lobe; RLL, right lower lobe. 
severe lymphocytopenia. Malnutrition may lower the sensitivity of the IGRA [14]. Three patients showed low serum albumin concentrations. The serum albumin concentration is a marker of nutritional status; these patients may have been suffering from malnutrition, which could explain these indeterminate results.

We used $10 \mathrm{~mm}$ as the TST cutoff considering the communal setting, relatively higher incidence in South Korea than in other developed countries, and large number of subjects with BCG scars (71.3\%). In the case of residents in high-risk congregate settings and recent immigrants from high-prevalence countries, $\geq 10 \mathrm{~mm}$ of induration is recommended as the criterion for a positive TST [16,29]. Most tuberculin skin reactions affected by BCG are less than $10 \mathrm{~mm}$ [30]. Although this can affect the diagnostic accuracy of the TST, the sensitivity and specificity were $97 \%$ (95\% CI, 91-99\%) and $88 \%$ (95\% CI, 74-96\%), respectively, when we applied $5 \mathrm{~mm}$ as the TST cutoff. Therefore, the change would be minimal if a cutoff of $5 \mathrm{~mm}$ were used in this study.

There are a few limitations in this study. First, the study population and clinical setting in this study were quite selective, and it is difficult to generalize this result to other situations. However, the study demonstrates the possibility that the TST and QFT-IT can play roles in determining TB disease for selected population. Second, comparisons with other age groups were not performed, and the diagnostic accuracy was evaluated for only one group. Third, the influence of BCG vaccination could not be evaluated because we did not know the accurate age of BCG vaccination of the subjects. However, school-age revaccination was abandoned in Korea 15 years ago when these subjects were 5 to 15 years old. For the past 15 years, BCG vaccination has been performed only at birth. Therefore, we can estimate that most subjects receive BCG vaccination at birth and that the effect on the TST is minimal.

\section{Conclusions}

Both the TST and QFT-IT showed high diagnostic accuracy for discriminating active TB from other pulmonary diseases. The diagnostic accuracy of these two tests did not differ significantly when applied to this clinical population of young, immunocompetent adults in whom neonatal BCG vaccination was common, there was no history of previous TB and in whom suspicion of TB was high. Therefore, in some selected populations, the TST and IGRA may be utilized as reliable aids to diagnose active TB, although the diagnosis should be confirmed by microbiologic, radiologic, and clinical methods.

\section{List of abbreviations}

TB: tuberculosis; HIV: human immunodeficiency virus; AFB: acid-fast bacilli; TST: tuberculin skin test; QFT-IT: QuantiFERON ${ }^{\mathbb{R}}{ }_{\circledast}$ TB Gold In-Tube assay; QFT-
2G: QuantiFERON-TB-2 Gold; IGRA: interferon- $\gamma$ release assay; LTBI: latent TB infection.

\section{Acknowledgements}

The study was supported by the Korean Military Medical Research Project from the ROK Defense Ministry. The funding sources had no role in study design, data collection and analysis, manuscript preparation, or the decision to submit the manuscript for publication.

\section{Author details}

${ }^{1}$ Department of Internal Medicine, Armed Forces Capital Hospital, Seongnam-si, Gyeonggi-do, Republic of Korea. ${ }^{2}$ The Korean Institute of Tuberculosis, Seoul, Republic of Korea. ${ }^{3}$ Department of Internal Medicine, Seoul National University Bundang Hospital, Seongnam, Republic of Korea.

\section{Authors' contributions}

JEL collected the data for this study, analyzed the data, and wrote the manuscript. HJK assisted with planning of this study. SWL planned this study, collected and analyzed the data, and wrote the manuscript. All authors read and approved the final manuscript.

\section{Competing interests}

The authors declare that they have no competing interests.

Received: 23 December 2010 Accepted: 18 April 2011

Published: 18 April 2011

\section{References}

1. World Health Organization(WHO) report 2009: Global tuberculosis control. [http://www.who.int/tb/publications/global_report/2009/key_points/en/], Accessed 1 Feb 2010.

2. World Health Organization(WHO): Global TB database. [http://apps.who.int/ globalatlas/predefinedreports/tb/index.asp?strSelectedCountry=KOR], Accessed 1 Feb 2010.

3. Diagnostic Standards and Classification of Tuberculosis in Adults and Children. This official statement of the American Thoracic Society and the Centers for Disease Control and Prevention was adopted by the ATS Board of Directors, July 1999. This statement was endorsed by the Council of the Infectious Disease Society of America, September 1999. Am J Respir Crit Care Med 2000, 161(4 Pt 1):1376-1395.

4. Laszlo A, Gill P, Handzel V, Hodgkin MM, Helbecque DM: Conventional and radiometric drug susceptibility testing of Mycobacterium tuberculosis complex. J Clin Microbiol 1983, 18(6):1335-1339.

5. Frieden TR, Sterling TR, Munsiff SS, Watt CJ, Dye C: Tuberculosis. Lancet 2003, 362(9387):887-899.

6. Rapid diagnostic tests for tuberculosis: what is the appropriate use? American Thoracic Society Workshop. Am J Respir Crit Care Med 1997, 155(5):1804-1814.

7. Kang YA, Lee HW, Hwang SS, Um SW, Han SK, Shim YS, Yim JJ: Usefulness of whole-blood interferon-gamma assay and interferon-gamma enzymelinked immunospot assay in the diagnosis of active pulmonary tuberculosis. Chest 2007, 132(3):959-965.

8. Kobashi Y, Mouri K, Yagi S, Obase Y, Miyashita N, Okimoto N, Matsushima T, Kageoka T, Oka M: Clinical utility of the QuantiFERON TB-2G test for elderly patients with active tuberculosis. Chest 2008, 133(5):1196-1202.

9. Park SY, Jeon K, Um SW, Kwon OJ, Kang ES, Koh WJ: Clinical utility of the QuantiFERON-TB Gold In-Tube test for the diagnosis of active pulmonary tuberculosis. Scand J Infect Dis 2009, 41(11-12):818-822.

10. Sester M, Sotgiu G, Lange C, Giehl C, Girardi E, Migliori GB, Bossink A, Dheda K, Diel R, Dominguez J, et al: Interferon-\{gamma\} release assays for the diagnosis of active tuberculosis: A systematic review and metaanalysis. Eur Respir J

11. Bianchi L, Galli L, Moriondo M, Veneruso G, Becciolini L, Azzari C, Chiappini E, de Martino M: Interferon-gamma release assay improves the diagnosis of tuberculosis in children. Pediatr Infect Dis J 2009, 28(6):510-514.

12. Baba K, Sornes S, Hoosen AA, Lekabe JM, Mpe MJ, Langeland N, DyrholRiise AM: Evaluation of immune responses in HIV infected patients with pleural tuberculosis by the QuantiFERON TB-Gold interferon-gamma assay. BMC Infect Dis 2008, 8:35. 
13. Diel R, Loddenkemper R, Meywald-Walter K, Gottschalk R, Nienhaus A: Comparative performance of tuberculin skin test, QuantiFERON-TB-Gold In Tube assay, and T-Spot.TB test in contact investigations for tuberculosis. Chest 2009, 135(4):1010-1018.

14. Pai M, Zwerling A, Menzies D: Systematic review: T-cell-based assays for the diagnosis of latent tuberculosis infection: an update. Ann Intern Med 2008, 149(3):177-184

15. Farhat M, Greenaway C, Pai M, Menzies D: False-positive tuberculin skin tests: what is the absolute effect of BCG and non-tuberculous mycobacteria? Int J Tuberc Lung Dis 2006, 10(11):1192-1204.

16. Mazurek GH, Jereb J, Lobue P, lademarco MF, Metchock B, Vernon A: Guidelines for using the QuantiFERON-TB Gold test for detecting Mycobacterium tuberculosis infection, United States. MMWR Recomm Rep 2005, 54(RR-15):49-55.

17. Im JG, Itoh H, Lee KS, Han MC: CT-pathology correlation of pulmonary tuberculosis. Crit Rev Diagn Imaging 1995, 36(3):227-285.

18. Im JG, Itoh H, Shim YS, Lee JH, Ahn J, Han MC, Noma S: Pulmonary tuberculosis: CT findings-early active disease and sequential change with antituberculous therapy. Radiology 1993, 186(3):653-660.

19. Im JG, Webb WR, Han MC, Park JH: Apical opacity associated with pulmonary tuberculosis: high-resolution CT findings. Radiology 1991, 178(3):727-731.

20. Landis JR, Koch GG: The measurement of observer agreement for categorical data. Biometrics 1977, 33(1):159-174.

21. Kang YA, Lee HW, Yoon HI, Cho B, Han SK, Shim YS, Yim JJ: Discrepancy between the tuberculin skin test and the whole-blood interferon gamma assay for the diagnosis of latent tuberculosis infection in an intermediate tuberculosis-burden country. JAMA 2005, 293(22):2756-2761.

22. Ildirim I, Hacimustafaoglu M, Ediz B: Correlation of tuberculin induration with the number of Bacillus Calmette-Guerin vaccines. Pediatr Infect Dis J 1995, 14(12):1060-1063.

23. Sepulveda RL, Heiba IM, King A, Gonzalez B, Elston RC, Sorensen RU: Evaluation of tuberculin reactivity in BCG-immunized siblings. Am J Respir Crit Care Med 1994, 149(3 Pt 1):620-624.

24. Rodrigues LC, Pereira SM, Cunha SS, Genser B, Ichihara MY, de Brito SC, Hijjar MA, Dourado I, Cruz AA, Sant'Anna C, et al: Effect of BCG revaccination on incidence of tuberculosis in school-aged children in Brazil: the BCG-REVAC cluster-randomised trial. Lancet 2005, 366(9493):1290-1295.

25. Raby E, Moyo M, Devendra A, Banda J, De Haas P, Ayles H, GodfreyFaussett P: The effects of HIV on the sensitivity of a whole blood IFNgamma release assay in Zambian adults with active tuberculosis. PLOS One 2008, 3(6):e2489.

26. Lee SS, Chou KJ, Su IJ, Chen YS, Fang HC, Huang TS, Tsai HC, Wann SR, Lin HH, Liu YC: High prevalence of latent tuberculosis infection in patients in end-stage renal disease on hemodialysis: Comparison of QuantiFERON-TB GOLD, ELISPOT, and tuberculin skin test. Infection 2009, 37(2):96-102.

27. Mori T, Sakatani M, Yamagishi F, Takashima T, Kawabe Y, Nagao K, Shigeto E, Harada N, Mitarai S, Okada M, et al: Specific detection of tuberculosis infection: an interferon-gamma-based assay using new antigens. Am J Respir Crit Care Med 2004, 170(1):59-64.

28. Kobashi Y, Mouri K, Obase Y, Fukuda M, Miyashita N, Oka M: Clinical evaluation of QuantiFERON TB-2G test for immunocompromised patients. Eur Respir J 2007, 30(5):945-950.

29. Targeted tuberculin testing and treatment of latent tuberculosis infection. This official statement of the American Thoracic Society was adopted by the ATS Board of Directors, July 1999. This is a Joint Statement of the American Thoracic Society (ATS) and the Centers for Disease Control and Prevention (CDC). This statement was endorsed by the Council of the Infectious Diseases Society of America. (IDSA), September 1999, and the sections of this statement. Am J Respir Crit Care Med 2000, 161(4 Pt 2):S221-247.

30. Wang L, Turner MO, Elwood RK, Schulzer M, FitzGerald JM: A meta-analysis of the effect of Bacille Calmette Guerin vaccination on tuberculin skin test measurements. Thorax 2002, 57(9):804-809.

\section{Pre-publication history}

The pre-publication history for this paper can be accessed here:

http://www.biomedcentral.com/1471-2334/11/96/prepub doi:10.1186/1471-2334-11-96

Cite this article as: Lee et al:: The clinical utility of tuberculin skin test and interferon- $\gamma$ release assay in the diagnosis of active tuberculosis among young adults: a prospective observational study. BMC Infectious Diseases 2011 11:96.

\section{Submit your next manuscript to BioMed Central and take full advantage of:}

- Convenient online submission

- Thorough peer review

- No space constraints or color figure charges

- Immediate publication on acceptance

- Inclusion in PubMed, CAS, Scopus and Google Scholar

- Research which is freely available for redistribution 